\title{
Influence of the Brazing Filler on the Microstructure of Ti6Al4V Joints
}

\author{
L. Gomes ${ }^{1}$ and A. Guedes ${ }^{1}$ \\ ${ }^{1 .}$ University of Minho, Department of Mechanical Engineering, MEMS-UMinho, Campus de Azurém, \\ 4800-058 Guimarães, Portugal.
}

The joining of simple Ti6Al4V made parts is often required to produce functional Ti6Al4V or multimaterial complex shape components [1]. Brazing is a commonly used technique to chemically join either similar or dissimilar materials. The mechanical properties of brazed joints are highly dependent on the nature, morphology and distribution of phases resulting from the reaction between the brazing filler and the base materials. These microstructural features are, in turn, manly function of the brazing temperature, brazing dwelling stage and type of the brazing filler. Therefore, in order to produce joints with adequate mechanical properties, proper selection of the brazing filler is fundamental and consequently, assessing its influence on the microstructure of joints is mandatory.

Ti6A14V joints were processed in vacuum (better than $10^{-4}$ mbar) using three different brazing fillers foils: Cusil (72Ag-28Cu, wt.\%), Ticuni (70Ti-15Cu-15Ni, wt.\%) and Tini 67 (67Ti-33Ni, wt.\%), with thicknesses of 100, 90 and $50 \mu \mathrm{m}$, respectively. Joints for microstructural and chemical characterization were cross-sectioned perpendicularly to the interface, cold mounted in epoxy resin and then prepared according to standard metallographic techniques. The microstructure and the chemical composition of the interfaces were analyzed on a FEI Nova 200 scanning electron microscope (SEM), equipped with an EDAX-Pegasus energy dispersive spectrometer. Energy dispersive spectroscopy (EDS) analysis were performed at an accelerating voltage of $15 \mathrm{keV}$, using conventional $\mathrm{ZAF}$ correction procedure included in the EDAX-Pegasus software. The minimum processing temperatures resulting in sound joints, for a dwelling stage of $30 \mathrm{~min}$ and heating and cooling rates set to $5{ }^{\circ} \mathrm{C} \cdot \mathrm{min}^{-1}$, were 820,1000 and $1080{ }^{\circ} \mathrm{C}$, for Cusil, Ticuni and Tini 67, respectively.

The typical microstructures of the brazed joints are shown in figures 1 to 3. Joints brazed with Cusil present a multilayered microstructure and no noticeable alterations were induced in either the microstructure or the chemical composition of the base Ti6A14V alloy. The brazed interface is around $150 \mu \mathrm{m}$ thick and presents near the base material a diffusion layer, followed by two thin reaction layers, all mainly composed of Ti and $\mathrm{Cu}$. Attending to the EDS analysis results in conjunction with the information provided by Ag-Cu-Ti and Al$\mathrm{Cu}-\mathrm{Ti}$ phase diagrams [2], these layers should consist of $\alpha \mathrm{Ti}+\beta \mathrm{Ti}(15 \mathrm{Al}-72.7 \mathrm{Ti}-4.9 \mathrm{~V}-0.8 \mathrm{Ag}-6.6 \mathrm{Cu}$, at.\%), $\mathrm{Ti}_{2} \mathrm{Cu}(5.1 \mathrm{Al}-61.3 \mathrm{Ti}-0.7 \mathrm{~V}-1.2 \mathrm{Ag}-31.7 \mathrm{Cu}$, at.\%) and $\mathrm{TiCu}(1.7 \mathrm{Al}-48.9 \mathrm{Ti}-0.4 \mathrm{~V}-3.0 \mathrm{Ag}-46.0 \mathrm{Cu}$, at.\%), starting from the base material towards the center of the joints. The central zone of the interface should consist of a $(\mathrm{Ag})$ matrix (1.8Al-1.9Ti-0.5V-86.4Ag-9.4Cu, at.\%) in which coarse $\mathrm{AlCu}_{2} \mathrm{Ti}$ particles $(9.2 \mathrm{Al}-24.6 \mathrm{Ti}-$ $1.8 \mathrm{Ag}-64.4 \mathrm{Cu}$, at.\%) are dispersed. It should be noted that $(\mathrm{Ag})$ will limit the maximum operating temperature of joints to around $300{ }^{\circ} \mathrm{C}$. Joining with both Ticuni and Tini 67 was only achieved above the $\beta$ transus $\left(995^{\circ} \mathrm{C}\right)$ of Ti6Al4V and induced the transformation of the microstructure of the base material from equiaxed to Widmanstätten. The resulting interfaces are much wider (around 330 and $500 \mu \mathrm{m}$ thick, for Ticuni and Tini 67, respectively) than after joining with Cusil and present a Widmanstätten morphology composed of $\alpha \mathrm{Ti}$ plates $\left(9.1 \mathrm{Al}-88.8 \mathrm{Ti}-2.1(\mathrm{Cu}, \mathrm{Ni})\right.$, at.\%) delineated by $\mathrm{Ti}_{2}(\mathrm{Cu}, \mathrm{Ni})$ particles $(4.8 \mathrm{Al}-77.7 \mathrm{Ti}-$ $1.3 \mathrm{~V}-16.2(\mathrm{Cu}, \mathrm{Ni})$, at.\%) for joining with Ticuni or by $\mathrm{Ti}_{2} \mathrm{Ni}$ particles $(6.6 \mathrm{Al}-71.8 \mathrm{Ti}-1.5 \mathrm{~V}-20.1 \mathrm{Ni}$, at.\%) when joining is carried out with Tini67 [3]. 


\section{References:}

[1] M.J. Donachie Jr, “Titanium: A Technical Guide, $2^{\text {nd }}$ Edition”, (ASM-International, Ohio). [2] "Handbook of Ternary Alloy Phase Diagrams", ed. P. Villars, A. Price, H. Okamoto, Vol. 3, (ASMInternational, Ohio).

[3] This work has been supported by FCT (Fundação para a Ciência e Tecnologia) in the scope of the project: PEst-OE/EEA/UI04436/2015.
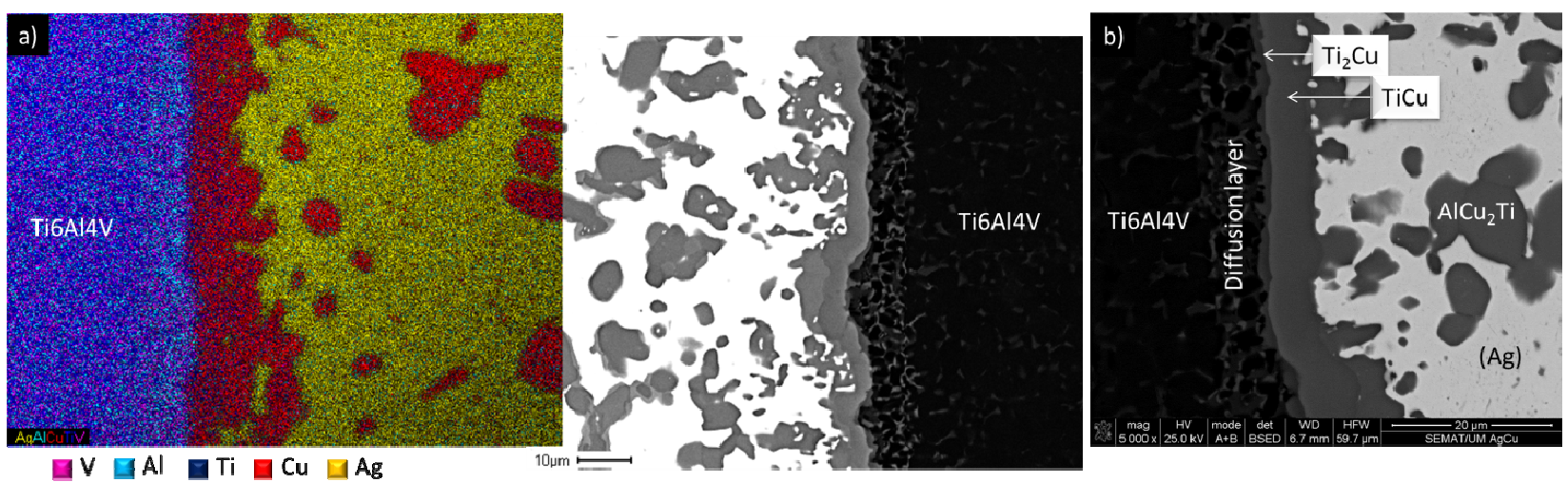

Figure 1. SEM images of the interface after brazing with Cusil: a) composed image showing an overlay of elemental distribution maps of one half of the interface and the backscattered electron image of the other half; $b$ ) magnification of the interface near the base material.
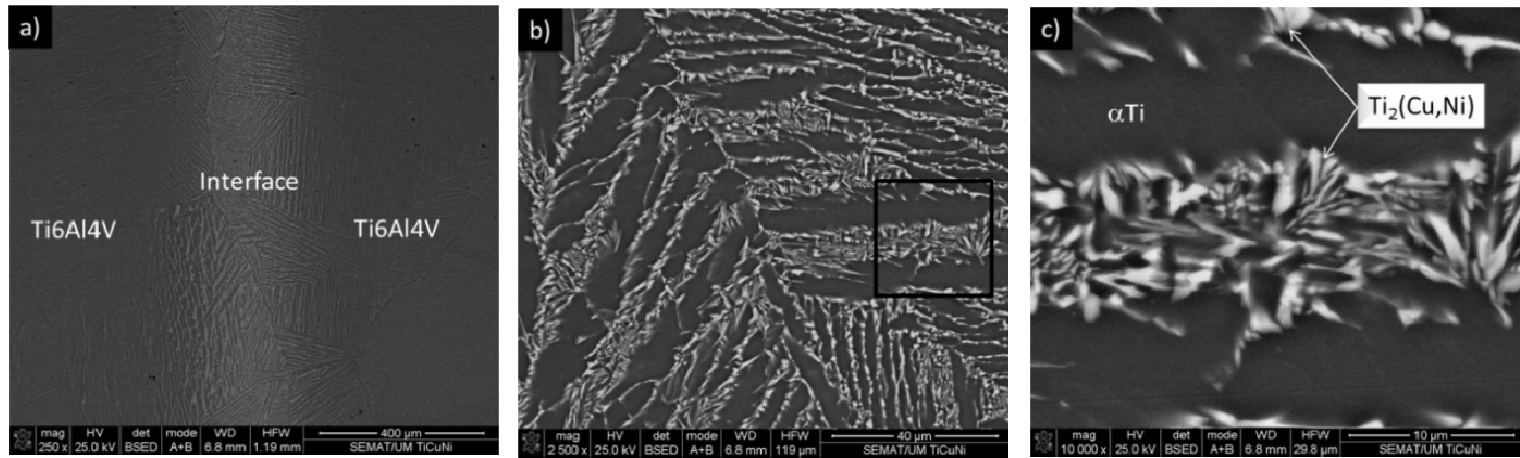

Figure 2. SEM images of the joint after brazing with Ticuni: a) global view; b) interface; c) magnification of the zone highlighted in b).
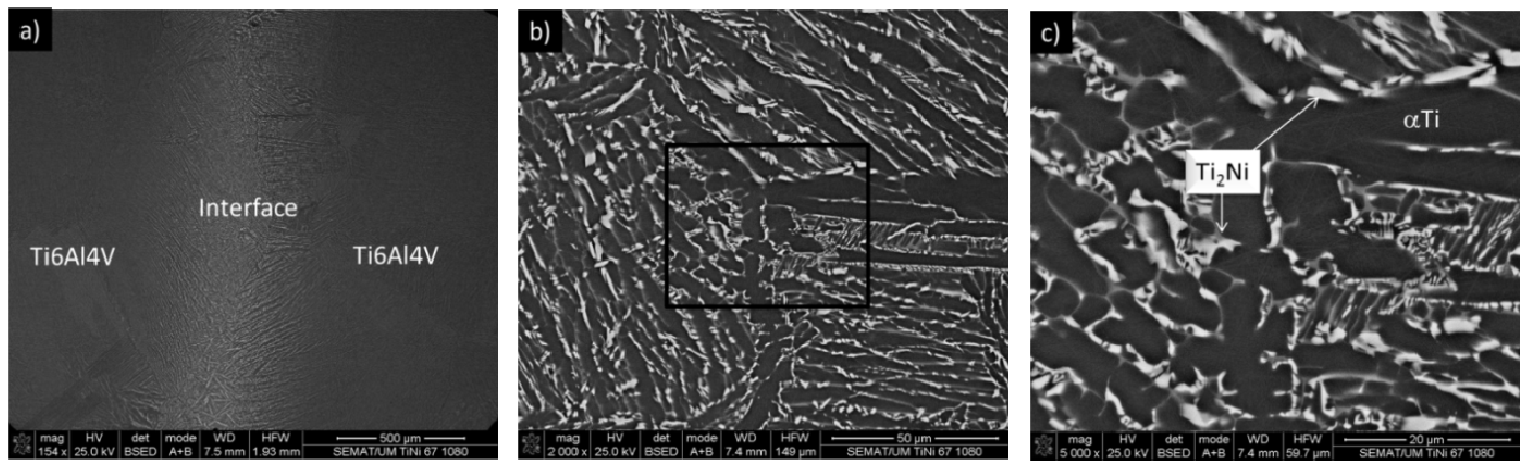

Figure 3. SEM images of the joint after brazing with Tini 67: a) global view; b) interface; c) magnification of the zone highlighted in b). 